\title{
0 DESCRÉDITO DISCURSIVO: prática docente da mulher negra
}

\section{THE DISCREDIT DISCURSIVE: teaching practice of the black woman}

\author{
Guilherme Costa Garcia Tommaselli \\ Instituto Federal de Educação, Ciência e \\ Tecnologia de Mato Grosso do Sul (IFMS-Três \\ Lagoas) \\ E-mail: guilherme.tommaselli@ifms.edu.br \\ Daiane Aparecida Fernandes da Silva \\ Especialista em Docência Profissional, \\ Tecnológica e Científica (IFMS - Três Lagoas) \\ E-mail: fernandesdaianes@outlook.com
}

\section{INTRODUÇÃO}

Este trabalho caracteriza-se como uma experiência de escrevivência, con— ceito cunhado pela prestigiada escritora negra Conceição Evaristo (2017), que aparece em sua obra Becos da Memória, que de acordo com SOARES e MACHADO (2017):

[...]significa, nesse sentido, contar histórias absolutamente particulares, mas que remetem a outras experiências coletivizadas, uma vez que se compreende existir um comum constituinte entre autor/a e protagonista, quer seja por características compartilhadas através de marcadores sociais, quer seja pela experiência vivenciada, ainda que de posições distintas. (MACHADO; SOARES, 2017, p. 206)

Portanto, este texto trata-se de uma reflexão sobre o descrédito discursivo que afeta a prática da mulher negra que exerce à docência, sendo a autora, mulher, docente e negra, que leciona no sistema regular de ensino, e teve em sua prática problemas semelhantes aos que serão abordados adiante.

O descrédito discursivo será pensado ao longo do texto, com referências conceituais negras, como o conceito de escrevivência de Evaristo, a intersec- 
cionalidade de gênero, classe e raça de Lélia Gonzalez (1983), ou o próprio conceito de lugar de fala de Djamila Ribeiro.

A análise da questão da mulher negra no Brasil nos coloca a necessidade de pensar sobre o recorte conceitual de raça e gênero, conforme nos confirma Lima (1995), quando afirma que as categorias raça e gênero são variáveis importantes para a análise da ascensão social dos diversos grupos sociais, a partir da educação. Ou seja, se vou tratar da experiência da mulher negra docente em sua prática, observando o descrédito imposto ao discurso desta, devo observar como a variável de raça e gênero, interfere neste sentido.

Sendo assim, é obvio e evidente que no Brasil que é um país com histórico escravocrata, a questão da raça não possa ser ignorada em qualquer que seja a análise social que se pretende fazer. Temos que observar, no que se refere a questão de gênero e como ela tem impacto na organização da experiência social brasileira. Acredito também, que não seja novidade aos leitores, que somos um país com altos índices de feminicídio, como confirma a Organização Mundial da Saúde (OMS), o Brasil teve em 2020 a quinta maior taxa de feminicídio do mundo. ${ }^{1}$

Deste modo, não é possível compreender o problema do descrédito discursivo da mulher negra docente em sua prática pedagógica, sem considerarmos as categorias de raça e gênero, como centrais e presentes em toda a análise.

Neste sentido, ao me propor a pensar a prática da mulher negra docente e o descrédito ao seu discurso pelos profissionais da educação, estabeleci como recorte o campo da educação e os problemas que ele apresenta no sentido de reproduzir as discriminações e preconceitos enraizados socialmente, como o racismo, que no caso do Brasil afeta a população negra e o patriarcado que afeta as mulheres, e todes que se identifiquem e sejam vistos socialmente como pertencentes ao gênero feminino.

Assim, nosso campo de análise é a escola, e como neste espaço está presente a estrutura racista e patriarca, que se reproduz no espaço da educação em que racismo e machismo deviam ser combatidos, tal como observa a ex-ministra da promoção da igualdade racial Nilma Lino:

\footnotetext{
${ }^{1}$ Disponível em: https://www1.folha.uol.com.br/opiniao/2020/12/feminicidio.shtml?origin=folha consultado em: 07 jan. 2021.
} 
A escola não é um campo neutro onde, após entrarmos, os conflitos sociais e raciais permanecem do lado de fora. A escola é um espaço sociocultural onde convivem os conflitos e as contradições. O racismo, a discriminação racial e de gênero, que fazem parte da cultura e da estrutura da sociedade brasileira, estão presentes nas relações entre educadores/as e educandos/as. (GOMES, Nilma, 1996, p. 06)

Quando falamos em racismo estrutural, nos referimos a permanência do racismo como forma estruturante de organização da sociedade brasileira, e especialmente, como forma estruturante da experiência vivenciada pelos negros, que thes é opressiva e desagradável, e que produz por muitas vezes um desejo de não ser reconhecido socialmente como tal.

Ou seja, afirmar que no Brasil há um racismo estrutural, é reconhecer que o fim da sociedade escravocrata não significou a equalização de negros e brancos, na verdade, essa divisão se mantém e pode ser observada até os dias atuais, por exemplo, quando ainda é considerado uma subversão da ordem uma negra concluir um curso universitário, visto que, a educação e especialmente a educação universitária, foram e ainda são privilégios garantidos primeiramente aos homens brancos, e espaço de disputa e luta dos negros e negras em busca de ascensão social em uma sociedade estruturalmente racista.

Portanto, o estruturalmente se refere a permanências de estruturas de saber-poder que impedem que ascensão social do negro através de barreiras sociais, políticas e econômicas, produzidas e experimentadas em consenso, por boa parte da população negra do país.

Diante desta premissa, tencionamos problematizar as dificuldades encontradas na prática docente da mulher negra, mas, além disso, discutiremos sobre o descrédito discursivo que esta tem em sua prática docente. Fizemos uma pesquisa bibliográfica com a intenção de procurar elementos que nos ajudem a reforçar a tese sobre o descrédito discursivo e intelectual das professoras negras.

Neste sentido, como apontamos, o Brasil se organizou na modernidade, conservando aspectos da estrutura colonial, que podem ser observados nas experiências cotidianas das mulheres negras, de modo que podemos observar esse processo de permanência como estrutural. Isso diz respeito ao racismo e ao machismo, dois fenômenos sociais, que se referem ao Brasil colonial que, por sua vez, era uma sociedade escravocrata e patriarcal. 
Neste contexto de permanência, no Brasil, ser mulher e negra é estar na base da pirâmide social, e quando consciente das injustiças que são fruto desta organização estrutural, é lutar contra as ideologias resultantes das teorias raciais, sobre as quais buscavam justificar o racismo cientificamente. Para Gomes,

Embora rebatidas hoje por cientistas e intelectuais, do ponto de vista teórico, essas teorias estão ainda introjetadas no nosso imaginário e na nossa prática social. Estudos na área da Sociologia e Antropologia demonstram a influência dessas teorias no pensamento brasileiro. Sendo assim, é importante que os educadores e as educadoras reflitam, discutam e atentem para a influência dessas teorias no pensamento educacional. Essa presença ainda é tão forte que foi possível percebê-la nos depoimentos das professoras entrevistadas e no discurso da escola. (GOMES, Nilma, 1996, p. 07).

Como dito a princípio, esse texto é pensado sob o conceito e podemos dizer método, da escrevivência de Conceição Evaristo. Deste modo, a reflexão que faço a seguir, tem uma parte de experiência própria, aquele que vivi na pele, mas que não é apenas particular, mas também é coletiva, pois se confirma no relato de outras mulheres negras docentes, como eu, e que a mim relataram o mesmo sentido em suas experimentações particulares, e que podemos encontrar também nos relatos presente no brilhante texto de Educação, Raça e Gênero: Relações imersas na Alteridade de Nilma Lino Gomes (1996).

O elemento raça não aparece concretamente como impedimento para a credibilidade de um discurso, porém na experiência docente, notamos, no entanto, que há diferença quando um professor (a) branco (a) traz dados alarmantes sobre o racismo no Brasil e consegue impactar emocionalmente determinado grupo de estudantes, e o mesmo não acontece quando é uma professora negra que faz o mesmo percurso, ou seja, aponta os dados da desigualdade racial que existe no país. Quando comento esta situação com professoras negras e elas me confirmam que já passaram por experiências parecidas, fica mais fácil atestar a funcionalidade da escrevivência como método, sem que esteja preso a dados estatísticos, não que eles não sejam importantes, mas, nos centraremos na experiência compartilhada e vivenciada de forma coletiva pelas mulheres negras, mesmo com diferentes intensidades.

Quando notamos, na cena narrada comumente por mulheres docentes negras, de como são reprovadas e contestadas em suas argumentações so- 
bre as questões raciais, ao passo que percebem, na mesma experiência, que quando o sujeito que enuncia os dados é branco, o contexto não se repete, podemos atestar aí, neste fato, uma faceta do racismo e do patriarcado, de modo a contribuir para a descredibilidade de quem fala, isto é, da negra. Se ambos sujeitos enunciam as mesmas questões e os mesmos dados, o que provoca a reação contrária da plateia ouvinte quando se trata de uma mulher negra como sujeito que enuncia?

Uma das possíveis explicações para essa questão pode ser dada se observamos o conceito de epistemicídio, termo cunhado pelo sociólogo Boaventura de Souza Santos e utilizado para pensar as questões do conhecimento proveniente dos negros no Brasil por Sueli Carneiro (2005).

Na perspectiva de SANTOS; MENEZES (2010) e CARNEIRO (2005), o epistemicídio é conceito que diz respeito ao apagamento, o assassinato, ou recusa de produções científica realizadas por povos não europeus. Mais grave que isso, o epistemicídio teve a função histórica de destruir as formas de saberes locais de modo que apresentasse o saber proveniente da Europa como único, legítimo, verdadeiro.

Portanto, o epistemicídio, é o fenômeno de apagamento da episteme negra, isto é, de forma sintética, da produção do conhecimento que é fruto do negro, do índio, do não europeu, mas, para além disso, de uma compreensão mais profunda, e que atinge níveis subconsciente: a de que o negro e a negra não sejam sujeitos capazes de enunciar um discurso verdadeiro, com credibilidade científica, independente se ocupam de forma legal o lugar de ensino, isto é, no nosso caso de análise, de professora.

É preciso ressaltar que o contexto histórico deste texto é de um notável avanço de forças conservadoras e de extrema-direita em todo mundo, e especialmente no Brasil com a vitória de Jair Bolsonaro em 2018, que possui uma agenda conservadora, e sem preocupação com a questão da justiça social, que inclui no caso brasileiro, sem dúvida, a pauta feminista e racial.

Deste modo, raça e gênero, são categorias de análises pertinentes a serem discutidas em espaços educacionais, porém, a eleição de Jair Bolsonaro representante das forças ultrarreacionárias e de extrema direita, demonstra que há um grande retrocesso na educação, em que temas como racismo e gênero passam a ser entendidos como ideologia, e tem sua importância 
contestada como elemento importante para o debate educacional. De forma mais acentuada, as posições patriarcais e racistas do atual presidente da república², "perdoadas" pelo judiciário nacional, reforçam o racismo e machismo estrutural brasileiro e aprofundam o problema de nosso interesse.

Dessa forma quando a mulher negra se depara com o racismo, seja ele estrutural, ou institucional (quando falamos de institucional, nos referimos ao âmbito acadêmico e educacional), percebemos a existência de uma dificuldade em "como defender-se", quais argumentos utilizar para esse tipo de enfrentamento? A falta de preparo, ou de dispositivos sociais e culturais que Ihe permitam contestar este fato, pode ser entendida como uma das causas para o silenciamento da mulher negra em sua prática, pois há uma linha tênue entre o lugar de fala e o discurso vitimista em nossa sociedade.

Quando me refiro à lugar de fala, estou me voltando ao conceito da filósofa Djamila Ribeiro (2017), que dá título ao seu livro O que é Lugar de Fala? Enquanto questionamento e não como afirmação. O conceito acabou popularizado, talvez por seu uso pela militância negra nas redes sociais, o que, neste cenário de polarização política, com o poder na mão da extrema-direita, levou a compreensões vazias e que nada se aproximam do que a filósofa aponta em seu texto.

Quando faz referência a lugar de falar, Djamila (2017) está falando sobre a possibilidade de uma experiência social narrada por aquele grupo de sujeitos que a experimenta de um modo particular, ou seja, no caso do racismo e do feminismo, por exemplo, categorias que nos interessam nesta análise, seria a compreensão de que a experiência social de uma mulher negra é em gênese e materialmente, impossível de ser vivida por uma mulher branca ou por qualquer homem.

Esse fato, autoriza esta mulher, a negra, a falar sobre as experiências raciais e de gênero, de um lugar da experiência vivenciada "na pele" do qual as brancas não podem falar. No limite, a mulher branca pode compreender

\footnotetext{
${ }^{2}$ O presidente Jair Messias Bolsonaro foi denunciado pela Procuradoria Geral da República pelo crime de racismo, por ter em ocasião pública comparado quilombolas à animais, ofendendo, portanto, a população afrodescendente do país. No entanto, o Supremo Tribunal Federal (STF) inocentou o presidente da acusação feita pela PGR, por diferença de um voto. Reportagem disponível em: https://g1.globo.com/politica/noticia/2018/09/11/stf-rejeita-denuncia-contra-jair-bolsonaro-por-crime-de-racismo.ghtml acesso em 05/06/2019.
} 
as opressões de ser mulher em uma sociedade estruturalmente machista, no entanto, ela não experimenta a opressão racial do mesmo modo, o que não quer dizer que ela não possa ser solidária as mulheres negras que experimentam a intersecção das opressões.

Neste cenário, de interseção de raça e gênero, observando o recorte que nos interessa que é o da mulher negra na educação e do descrédito discursivo que afeta a sua prática docente, optamos por realizar uma pesquisa bibliográfica, observando o que já foi apontado nas pesquisas sobre o racismo, procurando elementos históricos sociais que se apresentam desde o Brasil colônia (XVI) até os dias atuais (XXI), para compreender a trajetória da mulher negra, as causas que dessas dificuldades em exercer a docência, baseado no descrédito que alunos e superiores depositam em professoras, que têm como marcador a cor, em uma sociedade estruturalmente racista e machista.

\section{NEGRO: Anulação histórica}

SCHWARCZ (2012) traz uma importante reflexão em seu livro Nem preto, nem branco, muito pelo contrário, sobre a necessidade de branquear uma raça (negra), que por vezes não teve direito de escolha ao ser inferiorizada, uma vez que são tratados como pessoas "sem fé, nem Lei, e nem Rei", como pontua a autora.

Com histórico demasiadamente pejorativo, mulheres negras, seja retinta ou mestiça, sofrem até os dias atuais as consequências da escravização e inferiorização da raça, e consequentemente o apagamento social e cultural.

A teoria do branqueamento, do qual a base ideológica é a marginalização do negro, teve significativas contribuições para esse apagamento, pois nesta teoria havia a premissa de que quanto mais branco o indivíduo fosse, melhor, ou seja, uma visão produzida por influência europeia/americana, que apresenta o negro (a) e os não europeus, como inferiores, postulando a mestiçagem como possível solução, desde que esta mestiçagem tivesse como produto um ser humano mais próximo da tez branca.

Nina Rodrigues, escritor baiano, acreditava que o Brasil poderia ser então um país diferente, postulando a ideia da mestiçagem, como disfarce para a política estatal de branqueamento racial, e que a longo prazo teria como 
finalidade a dizimação da raça negra, para a construção de uma civilização nos moldes europeus. Neste registro, o Brasil teria que passar por um processo de branqueamento para que se tornasse socialmente aceitável e bem-visto aos olhos dos outros países da América.

A história oficial marca o final da escravidão negra no Brasil em treze de maio de 1888, e produz a narrativa de que após este dia, se colocou um ponto final na história da escravização. No entanto, a questão não era tão simples como se apresentava na história oficial, visto que é preciso considerar os aspectos da abolição e não retratação econômica dos negros escravizados, que no treze de maio de 1988, se tornaram a primeira grande população de desempregados do Brasil. Além disso, o racismo estrutural a que nos referimos neste texto, é no caso brasileiro consequência direta do processo de escravização da população negra.

Adiante seguimos a reflexão, observando que a ideologia eugenista e racista não era uma exclusividade do Brasil, como podemos observar com a declaração de Henry Fairfield Osborn em uma coluna no jornal The New Times em 26 de fevereiro de 1926, no qual ele reafirma as ideologias presentes na teoria darwinista.

\begin{abstract}
"O estoque de negroide é mais antigo que o caucasiano, e o asiático, algo que pode ser comprovado, através de uma análise não só do cérebro, do cabelo, e das características físicas, mas também dos instintos e da inteligência. O negro adulto comum, e seu padrão de inteligência enquanto adulto é semelhante ao de uma criança de 11 anos da espécie Homo Sapiens." (OSBORN, 1926, p. 129)
\end{abstract}

Percebe-se que há uma necessidade de descaracterizar intelectualmente o homem negro e a mulher negra, de forma a constituir através de falsas colocações científicas, justificativas para a inferiorização e até mesmo para a escravização. Essas teorias e afirmações deixaram marcas históricas e que ressoam no imaginário popular de parte da população brasileira até os dias atuais produzindo o racismo como fenômeno social estruturante que faz parte da organização da experiência social do brasileiro, e que é uma das grandes mazelas sociais a qual o país precisa enfrentar, inclusive para superar o avanço de forças reacionárias de extrema direita como as que ocupam o governo do país desde o golpe de 2016. 
O efeito destes eventos sociais, políticos, econômicos e histórico, é uma acentuada desigualdade, em que o negro ainda é na sociedade contemporânea nivelado a mão de obra barata e desqualificada, sendo em sua maioria a massa marginalizada. A sociedade ainda se disfarça sob o mito da democracia racial, reforçando a tese de que negros e brancos são tratados de forma igual nas relações sociais no Brasil, o que na prática não se observa, é apenas uma falácia.

Martiniano J. Silva (1995) em seu livro Racismo à Brasileira, relata sobre o racismo no Brasil, que acompanhado da falsa democracia racial, resultou na meritocracia e mais modernamente na política neoliberal, que é o mais difícil de se combater, pois se tratando do sistema hegemônico, é velada e dissimulada, negando assim a existência do racismo e pessoas praticando-o, fortalecendo o genocídio da população negra, e teorias de inferiorização perpetuadas até hoje.

Podemos afirmar também que autores da época pós-abolição inspirados por Gilberto Freire em "Casa grande e senzala" insistiam em passar uma versão histórica de uma relação amistosa entre o negro e o branco, ou seja, o opressor e oprimido, e afirmar ainda que mesmo após todas as atrocidades praticadas pelos senhores de engenho, os negros estendiam as mãos fraternas a eles, reforçando a ideia de que não havia preconceito racial no Brasil, e principalmente que havia de fato uma democracia racial.

(...) erigiu-se no Brasil o conceito de democracia racial; segundo esta, pretos e brancos convivem harmoniosamente, desfrutando iguais oportunidades de existência. (...) A existência dessa pretendida igualdade racial constitui o 'maior motivo de orgulho nacional' (...)". No entanto, "devemos compreender democracia racial como significando a metáfora perfeita para designar o racismo estilo brasileiro: não tão óbvio como o racismo dos Estados Unidos e nem legalizado qual o apartheid da África do Sul, mas eficazmente institucionalizado nos níveis oficiais de governo assim como difuso no tecido social, psicológico, econômico, político e cultural da sociedade do país. (NASCIMENTO, 1978, p. 54)

O tal mito se transformou em uma ideologia oficial, enraizada no país, havia o preconceito de ter preconceito, mas no que tange a vida social, econômica e cultural dos negros, nada mais era, do que uma barreira legal e institucional para ascensão da população negra, e dessa forma instalou-se a dificuldade dos negros (a) serem protagonistas da história, por não terem representatividade social em nenhum espaço de poder-saber. 


\section{MULHERES NEGRAS E BRANCAS: A discrepância social}

Segundo Chimamanda Ngozi Adichie em seu prefácio do livro "Sejamos todas feministas" ao falar de mulheres devemos sempre perguntar de que mulheres estamos falando. Mulheres não são um bloco único elas possuem pontos de partidas diferentes. Para a mulher negra a trajetória é definitivamente bem mais difícil, complexa, desigual, injusta, e cheia de desafios que as assombram até os dias atuais. Pensar em mulher negra na história é entender que há uma tentativa de deslegitimação da sua existência enquanto mulher, como também de sua produção intelectual, e social.

Em 1887 Rita Lobato Lopes, foi a primeira mulher a se formar no ensino superior no país, no curso de medicina. A escravização foi abolida no Brasil em 13 maio de 1888, ou seja, enquanto mulheres brancas lutavam pelo direito de estudar, as mulheres negras ainda estavam lutando para serem livres, e ter o mínimo de dignidade. O abismo é imensurável.

Precisamos entender que esse atraso ocorria de várias formas, no que se refere as lutas das mulheres negras, que tinha início na ausência total de qualquer controle sob seus próprios corpos, uma vez que, os estupros eram práticas naturalizadas, e consentidas socialmente, pois os senhores de escravizadas eram donos desses corpos, o que as deixavam sem escolhas e demasiadamente à mercê desses homens que se diziam cristianizados e detentores da moral e bons costumes.

Em 1934 as mulheres passaram a ter o direito de votar, e se candidatar a cargos públicos, porém nessa época os negros já sentiam as marcas históricas que a escravização deixava, de modo que eram proibidos de frequentar escolas, universidades e ter propriedades, fruto do racismo estrutural brasileiro.

Mulheres negras ganharam status de cidadãs livres, mas havia um sistema escravagista que deslegitimava essa liberdade, as mantendo sem emprego, sem assistência, excluída da lógica. Houve sim muita preocupação do Estado - não em incluir, mas de controlar e dominar a população negra neste contexto, como, por exemplo, a contravenção da vadiagem.

Essa ideologia racista enraizou-se no país, e continuava presente no intelecto dos senhores de escravos, bem como, no da sociedade brasileira. Nos dizeres de Gonzales "Desigual e combinado manteve a força do trabalho (ne- 
gra) na condição de massa marginalizada (em termos de capitalismo industrial monopolista) (...) competitivo, satelizado pelo setor hegemônico do monopólio". (GONZALEZ, Lélia, 1983, p. 32)

A mulher negra na sociedade pós abolição tem três lugares comuns: Ser mulher, ser negra e ser pobre, e essa premissa a empurra para ocupações manuais de baixo nível, como por exemplo, cargos de empregadas domésticas, babás, entre outros empregos não menos dignos, mas de baixa estrutura salarial, impossibilitando sua ascensão social, e uma possível mudança de status.

A condição de subjugação e esquecimento da mulher negra perdurou por boa parte do século XX. Não podemos dizer que houve neste período ou mesmo no período colonial, ausência de resistência. É importante notar que as mulheres negras ocupam também, um lugar significativo na resistência a escravidão e a própria organização desta resistência, como atestam os poucos relatos de Dandara dos Palmares, que comandava um exército de mulheres rebeldes. Tem que se destacar também, que o movimento negro também surge no contexto pós-abolição como um espaço possível para as mulheres negras, e como um grande protagonista da luta pelos direitos da população negra.

No entanto, é apenas em 1988, com o fim do regime militar e criação da Constituição Federal do Brasil, a "Constituição cidadã" que a situação da mulher foi repensada em termos legais e de direitos, com mais cuidado e com mais "particularidade". Em teoria a constituição de 1988 estabeleceu igualdade entre homens e mulheres, afirmando que são iguais em direitos e obrigações, no entanto o que se observou na prática foi o contrário, ou seja, a constituição não garantiu que na dinâmica social brasileira se operasse uma mudança estrutural sob os signos da raça e do gênero.

Outra questão fundamental sobre as relações raciais no país é apontada por Schwarz (2003) é a tradição escravagista, a tentativa de anular o preconceito, ou seja, no Brasil instalou-se "o preconceito de ter preconceito", não se assumir racista, e se dizer politicamente correto, enquanto se é racista, gerando o racismo velado, institucionalizado e sutil, a ponto de dificultar a punição.

As autoras pesquisadas apresentam algumas possibilidades de transformação dessa hierarquia que coloca a mulher negra na base, como a promoção efetiva da equidade de gênero, visibilidade, a participação social, e enegrecer o feminismo, nada mais são, do que formas de resistência a história 
de um país que se estruturou sob um sistema de escravização, e continua anulando o povo negro.

Segundo Djamila Ribeiro (2018, p.36) “O discurso universal é excludente, porque as mulheres são oprimidas de modos diferentes, tornando necessário discutir gênero com recorte de classe e raça, levando em conta as especificidades de cada um". Neste caso, se faz necessário o olhar interseccional para afirmar que mulheres negras têm uma visão a ser colocada em evidência, evitando que a história única continue a se disseminar e colocá-las em terceira pessoa de sua própria narrativa.

É o risco que assumimos aqui, é o ato de falar com todas as implicações. Exatamente porque temos sido faladas, infantilizadas, (Infan.: É aquele que não tem fala própria, criança falada em terceira pessoa) que neste trabalho assumimos nossa própria fala, ou seja, o lixo vai falar, e numa boa (GONZALES, Lélia, 1983, p. 225)

O feminismo no Brasil nunca abrangeu de forma significativa o que se refere a luta social da mulher negra, uma vez que enquanto mulheres brancas lutavam pelo direito de uma participação eleitoral, mulheres negras ainda lutavam para ser reconhecidas como mulheres e não objeto e mercadoria do homem branco. A necessidade de falar surge a partir do momento em que são banalizadas em seu lugar de fala.

O poeta palestino Mourid Barghouti teve uma de suas afirmações publicada no livro "O perigo da história única" escrito por Chimamanda, onde diz que o jeito mais fácil de destruir uma pessoa é contar sua história e colocá-la em segundo lugar, o que basicamente nos remete a pensar, a história do negro no Brasil.

Diante das evidências e fatos até aqui apontados, podemos afirmar sem medo de erros, que o racismo e a discriminação racial configuram sentidos implacáveis que alimentam um discurso racista, em que a mulher negra é vista por boa parte da sociedade sob um olhar pejorativo, mesmo que suas conquistas ultrapassem o lugar social que sistema racista determina como limite para ela.

\section{A CREDIBILIDADE DISCURSIVA DA PRÁTICA DOCENTE DA MULHER NEGRA}

Nenhuma de nós tinha permissão para pegar um livro ou tentar aprender, diziam que ficaríamos mais espertas do que eles se aprendêssemos alguma coisa, mas nós circulávamos por ali, pegávamos aquela velha cartilha Webster de capa 
azul e a escondíamos até a noite, então acendíamos uma pequena tocha e estudávamos, aquela cartilha. Nós também decorávamos o livro, agora sei ler e escrever um pouco (DAVIS, Ângela. 2016, p.76)

A passagem acima é um relato da ex-escrava Jenny Proctor que se encontra no livro Mulher, raça e classe de Ângela Davis. O relato que é de 1930, demonstra que para as mulheres negras escravizadas, a educação era um ato subversivo e de coragem. Mesmo que o processo de colonização tenha cerceado aos negros o conhecimento, entre as formas de resistência desta população, estava o reconhecimento do conhecimento como instrumento de poder necessário para lutar por melhores condições sociais.

Um dos fatores históricos que contribuem para colocar a mulher negra em descrédito discursivo é o fato de sua formação escolar e acadêmica ter sido negada por longos anos, o que a coloca no lugar de ter que reafirmar em sua contemporaneidade que isso já não faz parte de sua realidade, isto é, que são produtoras intelectuais, escritoras, poetisas, mestres, doutoras e principalmente, professoras, o nosso objeto de análise.

Ser professora estabelece uma responsabilidade racial indiscutível, independentemente da cor, visto que, em sociedades estruturalmente racistas como a brasileira não se pode pensar a profissão de professora desligado do caráter racial e de gênero. Há em nossa sociedade um número considerável de professoras negras, porém não se faz suficiente discutir somente o viés intelectual de professoras negras, pois o racismo na escola está longe de ser velado e sintetizado como afirma Nilma Lino:

A pesquisa realizada nos revela que existe uma ideologia racial presente no cotidiano escolar. Ela pode ser observada em frases aparentemente inocentes e tão presentes no imaginário e nas práticas educativas da nossa escola, como por exemplo: "Esta aluna é negra, mas é tão inteligente!" "Eu pensava que a professora do meu filho fosse assim... mais clarinha!" "A professora usa caneta preta porque é preta." (GOMES, 1996, p. 69)

Estão presentes no cotidiano escolar da professora negra discursos como estes, e frases que descaracterizam sua prática, sem mencionarmos a falta de confiança da parte da gestão escolar nos anos iniciais de sua carreira. As dificuldades encontradas na profissão docente por uma mulher negra são perpassadas por discriminações advindas do racismo estrutural que nos cerca diariamente e não propriamente de deficiências formativas. 
É alarmante saber que ainda é comum em pleno século XXI atos de racismo dentro das instituições escolares, lugar que em tese, deveria estar preocupado com questões de inclusão e sociabilidade entre professores e alunos independente de raça, gênero ou cor. Uma pesquisa realizada pelo Instituto Brasileiro de Geografia e Estatística (IBGE) em 2015 relata que a evasão de alunos negros no ensino fundamental e médio é bem maior do que se acredita, diminuindo também a possível chegada ao ensino superior:

Os resultados indicaram que 30\% da população negra (pretos ou pardos) não completava o Ensino Fundamental antes dos 16 anos. Além disso, só 56,8\% da população preta e 57,8\% parda entre 15 e 17 anos continuava no Ensino Médio. (IBGE/PNAD, 2015) $)^{3}$

Outro fator que coloca em evidência ideologias fundamentadas nas teorias raciais, são autores que contribuíram para que a deslegitimação e inferiorização da população negra se perpetuassem no imaginário social até os dias atuais. Teses como a de Nina Rodrigues escritor baiano, já mencionado, e conhecido fundamentalmente por reafirmar as diversas teorias raciais e científicas que legitimaram o racismo, colocam o intelectual do negro em discussão e descrédito. Portanto:

Raimundo Nina Rodrigues sustentou a tese de que raças ditas inferiores (negros, índios e mestiços) não poderiam ter o mesmo tratamento no código penal, justificando que elas possuíam mentalidades infantis, e, portanto, eram irresponsáveis. Considerou os mestiços indolentes, fracos e imprevidentes, devido o menor desenvolvimento de seus cérebros e herdeiros de um desequilíbrio mental. (BOLSANELLO, 1996. p. 159).

Lélia Gonzales (1983) afirma que o problema que está enraizado no Brasil e que esta população se considera branca ou quer sê-la, no entanto, estamos em um país majoritariamente negro, de cultura com forte influência negra africana, e que é anulada o tempo todo, pois há uma ideologia a ser sustentada, e ela se alimenta dia após dia do racismo estrutural.

É cultural no Brasil descaracterizar uma intelectual negra, e não a ver em lugares de evidência, como na $\mathrm{ABL}$ (Academia Brasileira de Letras), instituição fundada pelo escritor brasileiro e negro Machado de Assis, mas que, no

3 Disponível em: https://todospelaeducacao.org.br/noticias/o-combate-ao-racismo-passa-pela-escola/ consultado em: 7 de janeiro 2021 
entanto, não reconheceu até hoje a importância e significação da produção cultural da mulher negra, visto que nenhuma escritora negra foi escolhida para ser membro dela.

Esse é mais um elemento que comprova a tese que afirmamos sob o descrédito da mulher negra no meio acadêmico e cultural, ou seja, no mundo dos letrados, visto que temos em nosso país há uma vasta bibliografia de escritoras negras e premiadas, como Conceição Evaristo, que no ano de 2018 era uma das concorrentes para ocupar uma das cadeiras, mas que, não obteve êxito, e mais que isso, a vaga ficou com um homem branco. Fatos como este, denunciam o racismo e machismo estrutural do país ${ }^{4}$. Logo,

As intelectuais negras trabalhando em faculdades e universidades enfrentam um mundo que os de fora poderiam imaginar que acolheria nossa presença, mas que na maioria das vezes encara nossa intelectualidade como suspeita. O pessoal pode se sentir à vontade com a presença de acadêmicas negras e talvez até as deseje, mas é menos receptivo com negras que se apresentam como intelectuais engajadas. (HOOKS, 2003, p. 468)

Conforme Hooks nos acrescenta, a mulher negra enquanto intelectual, engajada ou não, tem sobretudo que lidar com o menosprezo que essa afirmação traz, ainda que não precise afirmar, e não precisa, mas devido a descaracterização do seu eu, enquanto mulher e negra que subverteu a ordem do determinismo, vê-se obrigada a rotular-se como tal. É notório que enfrentam o problema da questão de gênero e o peso da raça, para assim transparecer quem realmente são, no que se refere a intelectualidade. Djamila Ribeiro (2017) na sinopse de seu livro "O que é lugar de fala?" nos afirma:

"Fazendo o questionamento de quem tem direito à voz numa sociedade que tem como norma a branquitude, masculinidade e heterossexualidade, o conceito se faz importante para desestabilizar as normas vigentes e trazer a importância de se pensar no rompimento de uma voz única com o objetivo de propiciar uma multiplicidade de vozes."

De acordo com Lélia Gonzales (1983) falar do Movimento Negro implica no tratamento de um tema cuja complexidade, dada a multiplicidade de

4 Conceição Evaristo entrou na disputa para expor a falta de representatividade negra e feminina na centenária academia. Recebeu apenas um voto. Cacá, 22, e Pedro Corrêa do Lago, neto de Oswaldo Aranha, outros 11 votos. Disponível em: https://www.diariod ocentrodomundo.com.br/essencial/como-a-escritora-negra-conceicao-evaristo-perdeu-sua-cadeira-na-academia-brasileira-de-letras/. Acesso em: 05 jun. 2019. 
suas variantes, não permite uma visão unitária, nesse ínterim o feminismo negro é de conformidade com essa premissa fundamental por tratar dos assuntos e tentar defender os direitos relacionados não só a mulher, como o feminismo universal, mas também a mulher negra, por mais que insistem em generalizar, é primordial o trato específico do tema.

Neste contexto, de acordo com as discussões mais recentes sobre o feminismo negro, algumas delas encabeçadas por Djamila Ribeiro, que tem um livro com o título quem tem medo do feminismo negro? e O que é lugar de fala? Existe uma relação de poder dentro do movimento feminista, controlado pelas mulheres brancas de elite, no sentido de levantarem suas pautas como únicas. Então, há uma relação ainda de um racismo muito forte no movimento.

As opressões se inter-relacionam gerando outros meios de opressão, dessa forma se faz necessário ter um meio de resistência e neste caso o feminismo negro além de fazer-se eficaz, tem um vasto campo teórico e crítico de produção intelectual de mulheres negras na sociedade brasileira, de forma única e isolada.

Destarte a feminilidade negra precisa de uma pauta específica, e que abranja a complexidade da sua resistência, e que dê notoriedade para a produção intelectual dessas mulheres, enquanto acadêmicas, ou escritoras, e é claro, sem desmerecer o feminismo hegemônico, pois através dele houve também diversas conquistas, inclusive o acesso à educação superior.

Portanto pensar a ressignificação e a representatividade é garantir que a mulher negra ocupe o espaço que lhe foi negado devido a escravização, que tenha respeito enquanto mulher e docente, que o diploma de ensino superior não seja uma subversão da ordem, e mais que isso, que ela passe a pertencer a cargos de poder na sociedade.

\section{CONSIDERAÇÕES FINAIS}

No presente trabalho desenvolveu-se uma pesquisa bibliográfica para reafirmar a existência de um descrédito discursivo da prática docente da muIher negra, observando como as reflexões sobre raça e gênero, nos ajudam a chegar à conclusão de que isso se deve a uma multiplicidade de fatores, entre os quais, ao nosso ver os mais importantes são: a uma construção histórica 
e cultural de uma sociedade escravagista e racista aliada as teorias raciais do século XIX e reforçadas ao longo dos tempos, e a estrutura colonial patriarcal, que produz o fenômeno do machismo, e produz a inferiorização social do gênero feminino.

A nossa investigação se propôs a buscar em obras acadêmicas e discursos de ativistas do movimento negro, elementos para entender e explicar esse processo, que se dá em resultado da escravização e de uma sociedade com ideologia escravocrata.

Dentre as diversas políticas com intuito de reafirmarem o racismo no Brasil, nosso foco esteve voltado para as quais atrasaram o andamento acadêmico do negro e consequentemente de forma mais profunda da mulher negra. Acreditamos ser importante fazer a ressalva, até para que não haja generalização das reflexões apresentados, que há exceções, como a camada pequena, mas existente, de mulheres negras pertencentes a elite do país, e não compartilham das mesmas especificidades aqui apresentadas.

Temas como o problema da história única do povo escravizado, a necessidade de falar sobre o racismo e maneiras de lidar com esse problema deveriam ser trabalhados como tema prioritário nas escolas, revelando aos estudantes negros (a) a necessidade urgente de se promover a igualdade racial e de gênero, como condição de desenvolvimento de um país menos injusto. Nesse caso, a educação que pretenda realizar esse enfrentamento não pode desistir de destacar as diferenças do feminismo universal e do feminismo negro, deixando objetivamente claro que a mulher negra necessita de um discurso particular.

Trabalhar essas questões em sala sem embasamento teórico e sem formação específica, acaba na reprodução da história única, e senso comum, o que não é justo para um país com tanta produção intelectual de qualidade disponível.

No que se refere as instituições escolares, é necessário fazer com que se cumpra a Lei 10.639/03, que é o instrumento legal que permite que o debate sobre o racismo e história da escravização sejam elementos centrais no currículo escolar. No entanto, a efetividade da lei, depende da ação de educadores dispostos a pôr em prática uma educação antirracista e antimachista. 
Além do processo educacional em si, é fundamental que se avance na representatividade negra nos espaços de poder. Neste sentido, figuras como Nilma Lino não deveriam ser exceções, mas compor de forma natural, parte do quadro político e educacional do país.

Para se combater o racismo estrutural é fundamental se movimentar e transformar as instâncias do poder. No caso brasileiro, a sociedade colonial patriarcal e racista, nos obriga a fazer um movimento duplo, ou seja, é preciso combater também, o machismo estrutural.

Nessa ceara, a mulher negra, se encontra diante do maior desafio na disputa por espaço social e de forma mais acentuada, de descrédito intelectual. Deste modo, seria fundamental o desenvolvimento de políticas públicas que estimulassem a promoção da igualdade étnico-racial e de gênero em instâncias de poder, de tal forma que de não seja exceção a eleição representantes negras para tais postos, pois mesmo que existam, há ainda poucas gestoras negras ocupando cargo de poder e decisão nas escolas.

Essa inversão de lugares do poder é fundamental para diminuir o racismo e o descrédito intelectual do negro (a), não só nas escolas que é o nosso objeto de estudo, mas em qualquer outro âmbito empregatício.

A mulher negra tem capacidade intelectual e física para ocupar com maestria qualquer cargo que lhe for de interesse, por mais esdruxulo que seja ter que afirmar isto no século XXI.

Vale lembrar que o feminismo negro, e os movimentos sociais voltados para o benefício da causa não são suficientes, sendo estes uma das possibilidades de lutas que buscam cobrar a dívida escravagista no Brasil, é necessário ainda que se façam valer as leis até aqui conquistadas, e colocar em evidências as intelectuais negras brasileiras, que como demonstrado nesse trabalho, formam um extenso histórico bibliográfico, que não é pouco conhecimento nacional e acadêmico.

A prática docente da mulher negra e o descrédito discursivo requer uma mudança de postura social, que começa dentro das escolas e em todos os outros âmbitos de convívio social, do qual ela deve se colocar em evidência, fazer ouvir sua voz, se colocar em primeira pessoa em sua narrativa histórica, enfrentando através do discurso embasado nos movimentos 
sociais de lutas negras e nas referências acadêmicas e científicas negras, o racismo e patriarcado estrutural que afeta sua prática profissional e sua própria existência.

Portanto ser mulher e negra no Brasil é buscar quebrar os estereótipos, a folclorização estabelecida pela branquitude, no sentido de estabelecer a representatividade, bem como, reconhecer o quanto as mulheres contribuíram e contribuem para esse país miscigenado e com uma população composta por maioria negra.

Resumo: Neste trabalho procuramos refletir sobre a mulher negra docente e o descrédito discursivo em sua prática docente, quais os possíveis motivos? Como ele acontece? Assim, procuramos explorar as causas do descrédito discursivo na prática docente da mulher negra vinculados com o racismo e machismo estrutural que afetam o Brasil. Para tanto fizemos uma pesquisa bibliográfica e explorando preferencialmente autoras militantes do movimento negro brasileiro, como Djamila Ribeiro e Lélia Gonzáles para tentar explicar esse fenômeno desde a fase da escravização que se deu em meados do século XVI, e pontuando questões raciais ainda existentes no século XXI. Através das pesquisas realizadas observou-se que o feminismo universal não abrange as especificidades da mulher negra, e tampouco se fazem valer as leis de defesa étnico-raciais no Brasil. É preciso exatidão e objetividade quando se fala de gênero, e principalmente quando este é associado à raça, e à docência.

Palavras-chave: Professora Negra; Racismo estrutural; Prática docente.

\begin{abstract}
In this work we try to reflect on the black woman teacher and the discursive discredit in her teaching practice, what are the possible reasons? How does it happen? Thus, we seek to explore the causes of discursive discredit in the teaching practice of black women linked to the racism and structural machismo that affect Brazil. To this end, we carried out a bibliographic research and preferentially explored militant authors from the Brazilian black movement, such as Djamila Ribeiro and Lélia Gonzáles to try to explain this phenomenon since the phase of enslavement that took place in the middle of the 16th century, and punctuating racial issues that still exist in the 21st century. Through the research carried out, it was observed that universal feminism does not cover the specificities of black women, and neither do ethnic-racial defense laws in Brazil. It takes accuracy and objectivity when it comes to gender, and especially when it is associated with race, and teaching.
\end{abstract}

Keywords: Black Teacher; Structural racism; Teaching practice.

\title{
REFERÊNCIAS
}

BOLSANELLO, M. A. Darwinismo Social: eugenia e racismo. Educar. 1. ed. Curitiba: UFPR, 1996. BORGES, R. S; CARNEIRO, S. Retratos de um Brasil negro. São Paulo: Selo Negro, 2009.

BEAUVOIR, S. O segundo sexo. Tradução: Sérgio Milliet. Rio de Janeiro: Nova Fronteira, v. II, 1980.

CARNEIRO, A. S. A construção do Outro como não-ser como fundamento do ser. 2005. Tese (Doutorado em Educação) - Universidade de São Paulo, São Paulo, 2005.

DAVIS, A. Mulher, raça e classe. trad. Plataforma Gueto. 2003. Disponível em: https://plataformagueto.files.wordpress.com/2013/06/mulheres-rac3a7a-e-classe.pdf. Acesso em: 07 jan. 2021.

EVARISTO, C. Becos da Memória. Rio de Janeiro: Pallas, 2017. 
GOMES, N. L. Educação, Raça e Gênero: Relações imersas na Alteridade. Disponível em: XX Reunião Brasileira de Antropologia e I Conferência: Relações. Étnicas e Raciais na América Latina e Caribe, em abril de 1996.

GONZÁLEZ, L. Epígrafe de abertura do texto "Racismo e sexismo na cultura brasileira". In: Movimentos sociais urbanos, minorias étnicas e outros estudos. Brasília: ANPOCS, 1983.

GONZÁLEZ, L. Cultura, etnicidade e trabalho: efeitos linguísticos e políticos da exploração da mulher. Comunicação apresentada no VIII Encontro Nacional da Latim American Studies Association. 1979.

HOOKS, B. Intelectuais negras. Estudos Feministas. 2. ed. Dossiê: Mulheres Negras. Florianópolis, 1995.

JESUS, C. M. Quarto de Despejo. Edição Popular. Rio de Janeiro: Editora Francisco Alves, 1963.

LIMA, M. Trajetória educacional e realização socioeconômica das mulheres Negras. Revista Estudos Feministas, Rio de Janeiro, IFCS/ UFRJ, v. III, 1995.

NASCIMENTO, A. O Genocídio do Negro Brasileiro: processo de um racismo mascarado. Rio de Janeiro: Paz e Terra, 1978.

OSBORN, F. H. The Revolution of Humans Races. Natural history, New York, v. 26, 1926.

RIBEIRO, D. O que é lugar de fala? Belo Horizonte (MG): Letramento; justificando, 2017.

RODRIGUES, N. Os Africanos no Brasil. São Paulo: Cia Editora Nacional, 1935.

SCHWARCZ, L. M. Nem preto nem branco, muito pelo contrário: cor e raça na sociabilidade brasileira / Lilia Moritz Schwarcz. 1. ed. São Paulo: Claro Enigma, 2012.

SILVA, M. J. Racismo à Brasileira: Raízes Históricas: um novo nível de reflexão sobre a história do Brasil. 3. ed. São Paulo: Editora Anita, 1995.

SOARES, L. V.; MACHADO, P. S. "Escrevivências" como ferramenta metodológica na produção de conhecimento em Psicologia Social. Rev. psicol. polít., São Paulo, 2017. Disponível em: http://pepsic.bvsalud.org/scielo.php?script=sci_arttext\&pid=S1519549X2017000200002\&lng= pt\&nrm $=$ iso.

Recebido em Setembro de 2020

Aprovado em Fevereiro de 2021 